\title{
Investigation of Surface Self-Nanocrystallization in 0Cr18Ni9Ti Induced by Surface Mechanical Attrition Treatment
}

\author{
Guangmin Sheng \\ College of Materials Science \& Engineering, Chongqing University, Chongqing 400044, China \\ Correspondence should be addressed to Guangmin Sheng, gmsheng@cqu.edu.cn
}

Received 22 March 2011; Accepted 28 April 2011

Academic Editors: H. Bei, E. Le Bourhis, and X. Zeng

Copyright ( $) 2011$ Guangmin Sheng. This is an open access article distributed under the Creative Commons Attribution License, which permits unrestricted use, distribution, and reproduction in any medium, provided the original work is properly cited.

By means of shot peening (a form of surface mechanical attrition treatment (SMAT)), a nanostructured surface layer was formed on the cross-sectional surface of a 0Cr18Ni9Ti bar. Several characterization methods in common use, such as OM, SEM, TEM, and $\mathrm{XRD}$, were adopted to systematically characterize microstructure features of the nanostructured layer in the top surface of the sample. Microstructure features of the surface layer, which appeared mainly as severely deformed and contained grains with size in nanomagnitude, could be intuitionisticly presented through OM, SEM, and TEM. XRD was a useful method and average grain size and mean microstrain could be quantitatively calculated from the XRD patterns. In addition, analyses of XRD patterns showed that there was a martensite transformation in the top surface layer. Microhardness distribution along the depth of the deformation layer from the top surface showed that the surface self-nanocrystallization (SSNC) layer is a gradient structure and that the hardness of the top surface is greatly enhanced due to grain refinement and work hardening.

\section{Introduction}

Nanocrystalline(nc) materials refer to those materials which are structurally characterized by grains with size less than $100 \mathrm{~nm}$. It is not a new concept to us now and many preparation methods for nanocrystalline(nc) materials have hitherto been developed, for example, the consolidation of ultrafine powders produced by different techniques [1], the crystallization of amorphous precursors [2], and electrodeposition [3]. However, these methods have some common limitations [4], such as contamination of inner interface, porosity, limited size and shape of materials prepared, and high preparation cost. Consequently, these technologies for preparing nanocrystalline(nc) materials have little practical value and therefore are not so widely applied on an industrial scale.

However, researchers have developed a new approach in recent years-surface mechanical attrition treatment (SMAT) induced surface self-nanocrystallization(SSNC) [5, 6] - to obtain bulk nanocrystalline materials. This processing route can effectively conquer those deficiencies encountered by preparation methods mentioned above. The essence of SMAT is to give rise to severe plastic deformation
(SPD) to the surface of metals. In principle, technologies that can induce SPD in the surface of metals are useable for SMAT. Institute of Metal Research(IMR) Chinese Academy of Sciences has come up with several ways (SMAT, USSP, ECAP, and etc.) to achieve SMAT-induced SSNC in metals and has created corresponding setups as well. According to open literature IMR and other researchers have published, SSNC induced by SMAT has been successfully implemented in many metals and alloys, such as Fe and low carbon steels [7], Al and aluminum alloys [5, 8], $\mathrm{Cu}[5], 304[5,9,10]$ and $316 \mathrm{~L}[10]$ stainless steel, Ti and titanium alloys $[4,11]$, and Cobalt [12].

Research results indicated that nanocrystalline(nc) materials have many novel properties relative to their coarsegrained counterparts. For instance, experiment measurements indicated that mechanical and tribological properties and performance of the materials could be significantly enhanced by means of the SMAT-induced SNC [13]. Especially, superficial diffusion ability is greatly improved after surface grains are refined to nanomagnitude [14-16]. It is a popular conclusion that the global and superficial properties of engineering materials can be effectively upgraded through SMAT-induced SNC $[17,18]$. The application of SSNC in 


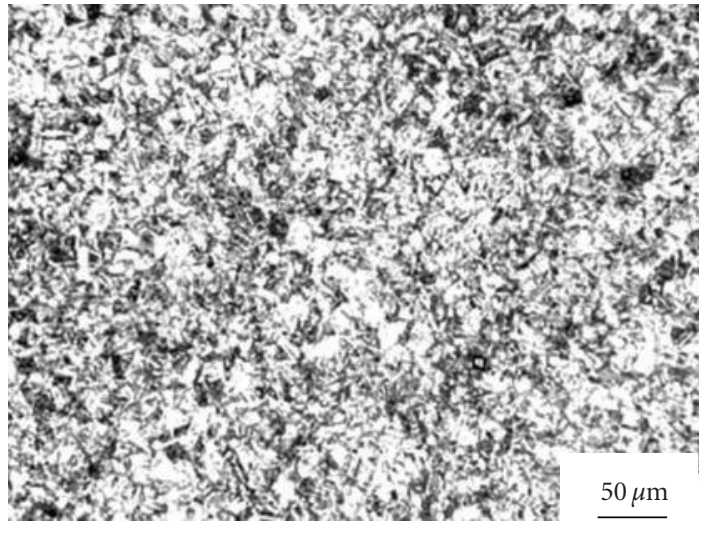

(a)

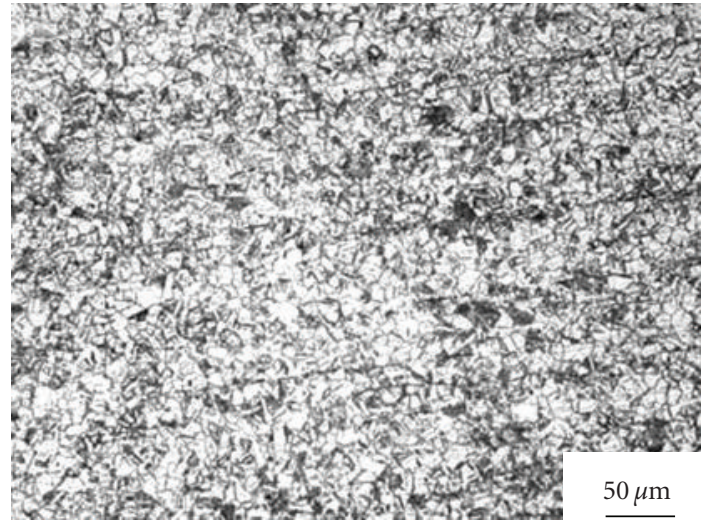

(b)

Figure 1: The as annealed structure of 0Cr18Ni9Ti (a) cross section and (b) longitudinal section.

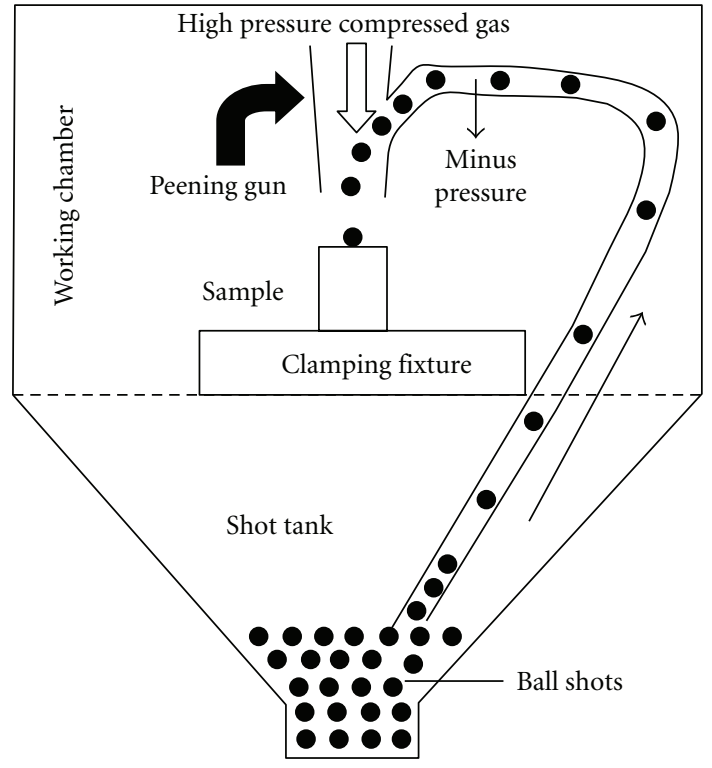

(a)

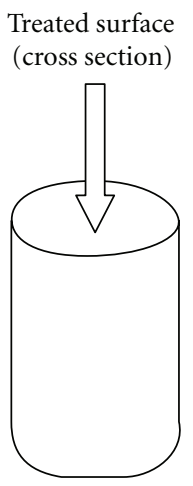

(b)

FIGURE 2: A schematic illustration of (a) the principle of the SMA treatment setup and (b) sample treated.

traditional engineering metal materials has great potential and bright prospect in industry.

This paper mainly concerns preparation and characterization of the SNC layer in the surface of $0 \mathrm{Cr} 18 \mathrm{Ni9Ti}$. $0 \mathrm{Cr} 18 \mathrm{Ni}$ 9Ti is comprehensively used in industry, and there is a demand to bond $0 \mathrm{Cr} 18 \mathrm{Ni}$ iTi with another heterogeneous metal or alloy, for example, TA17 (a titanium alloy, 4\% Al, $2 \% \mathrm{~V}$ ). The bonding of $0 \mathrm{Cr} 18 \mathrm{Ni}$ Ti and another dissimilar metal or alloy is a kind of diffusive bonding, and it greatly depends on the diffusion ability of the surface atoms. Thus, our terminal goal is to achieve diffusive bonding of 0Cr18Ni9Ti and another dissimilar metal or alloy, taking advantage of excellent superficial diffusion ability of the SNC layer.

\section{Experiment}

2.1. Sample. A $0 \mathrm{Cr} 18 \mathrm{Ni} 9 \mathrm{Ti}$ bar $(\Phi 12 \mathrm{~mm} \times 30 \mathrm{~mm})$ was subjected to the SMA treatment in order to achieve an nc surface layer. Its chemical composition was listed below in Table 1.

Before SMA treatment, two pretreatments were made to the sample. (1) Annealing: the sample was annealed at $1373 \mathrm{~K}$ for $60 \mathrm{~min}$ for diminishing the effect of mechanical processing and obtaining homogeneous coarse grains. The grain size of the annealed sample is on average $15 \sim 20 \mu \mathrm{m}$. The as annealed structure was showed below in Figure 1(a) and Figure 1(b). It was mainly composed of equiaxed austenite grains, and there were annealing twins in some 


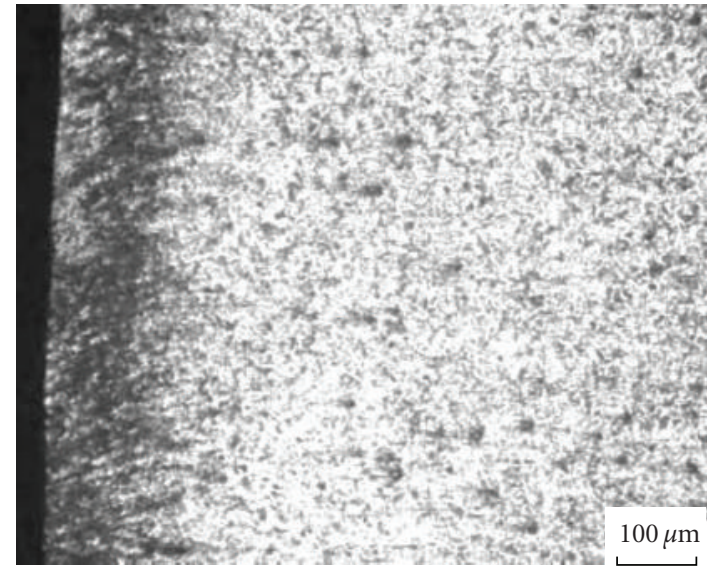

(a)

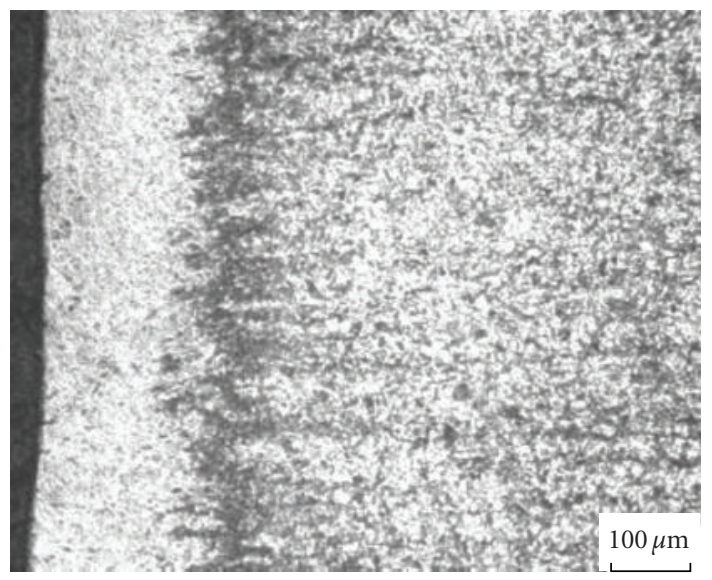

(c)

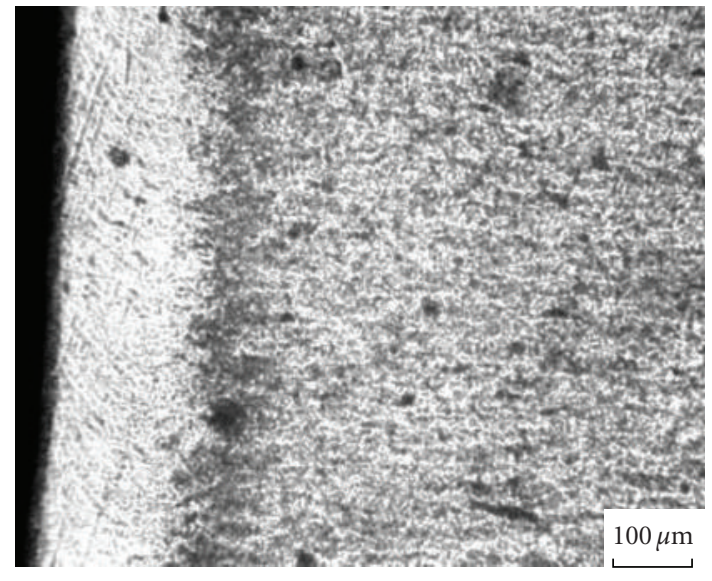

(b)

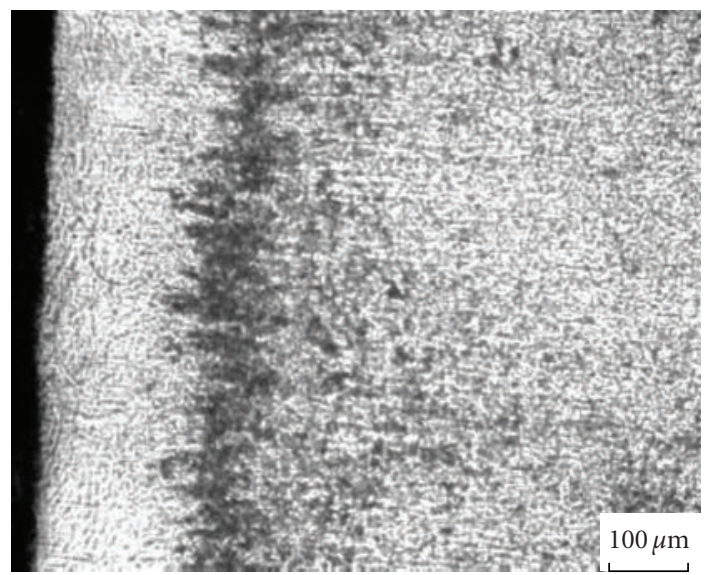

(d)

Figure 3: Cross-sectional OM micrographs close to the SMATed surfaces under different treatment time: (a) $1 \mathrm{~min}$, (b) 5 min, (c) 9 min, and (d) 13 min.

grains. (2) Polishing: the cross-sectional (circular plane) surface was polished manually with silicon carbide papers to 1000\# and then mechanically polished with $\mathrm{Al}_{2} \mathrm{O}_{3}$ polishing powder. Good surface finish can be obtained through this procedure.

2.2. SMA Treatment. SMA treatment was performed on a special shot-peening machine. Figure 2 shows a schematic illustration of the principle of the SMA treatment setup. Cast iron balls of $1.5 \mathrm{~mm}$ in diameter were threw with high velocity to the cross section surface of the cylinder-shaped sample under peening pressure of about $0.6 \mathrm{Mpa}$. Treatment time is a key parameter controlled during experiment. In order to investigate effects of treatment time on characters of the SNC layer, four kinds of treatment time were chosen for comparison, namely, $1 \mathrm{~min}, 5 \mathrm{~min}, 9 \mathrm{~min}$, and $13 \mathrm{~min}$, respectively. After the SMA treatment, the roughness of the surface increased significantly and the cross section of the sample became a cambered surface with introflexion edge.
2.3. Microstructural Characterization. Cross-sectional and longitudinal observations of the treated samples were performed on an optical microscope $(\mathrm{OM})$ and an FEI NOVA NANOSEM 400 scanning electron microscope(SEM).

Meanwhile, microstructure features in the surface layer were characterized by using a Philip Tecnai 20 transmission electron microscope (TEM, operating at a voltage of $200 \mathrm{KV})$. Plane-view thin foils for TEM observations were prepared by means of cutting, grinding, dimpling, and a final ion thinning at low temperatures. Plane-view thin foils were cut parallel to the treated surface (cross section), about $0.2 \mathrm{~mm}$ in thickness.

$\mathrm{X}$-ray diffraction (XRD) analysis of the surface layer in the SMA treated sample was performed on a D/Max-1200 XRay diffractometer, with $\mathrm{Cu} K_{\alpha}$ radiation (wavelength $\lambda_{K \alpha 1}=$ $0.154056 \mathrm{~nm}, \lambda_{K \alpha 2}$ was eliminated by a graphite monochromator using its (0002) reflection). Slit parameters of the diffractometer were $1^{\circ}-1^{\circ}-0.30 \mathrm{~mm}$. Full Wave at Half Maximum (FWHM) of diffraction peaks was measured by MDI Jade5.0 (a famous X-ray analysis software). The average grain 


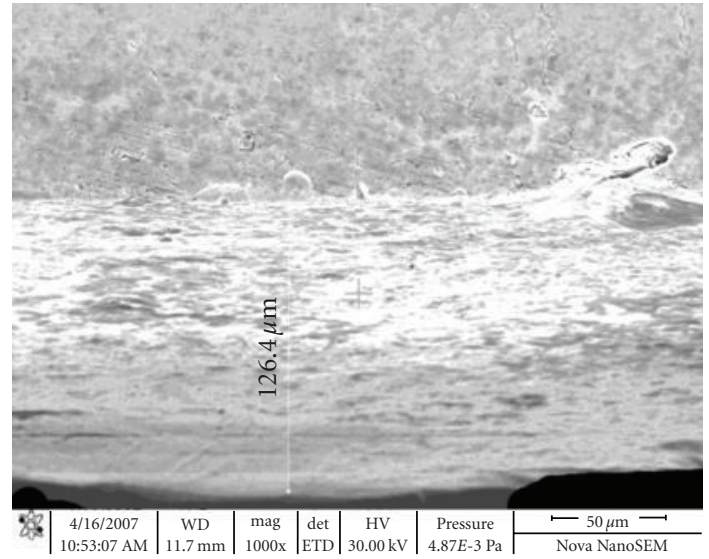

(a)

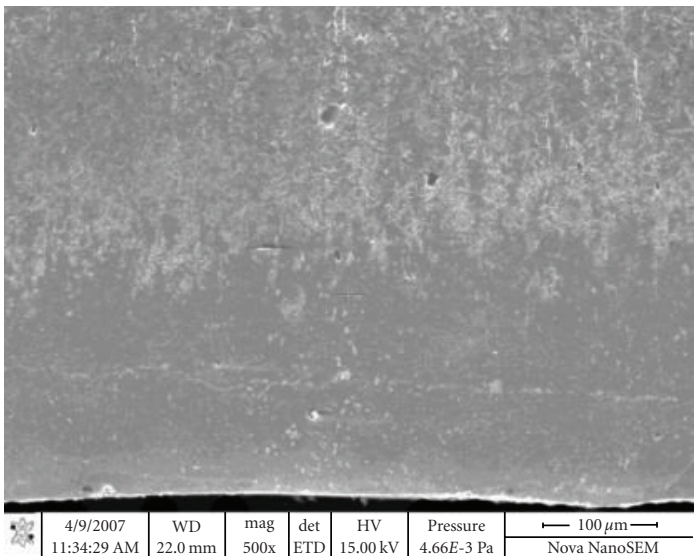

(c)

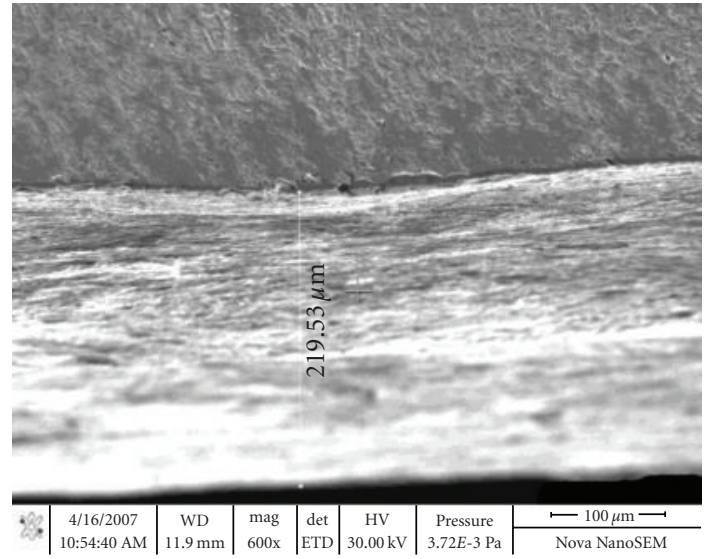

(b)

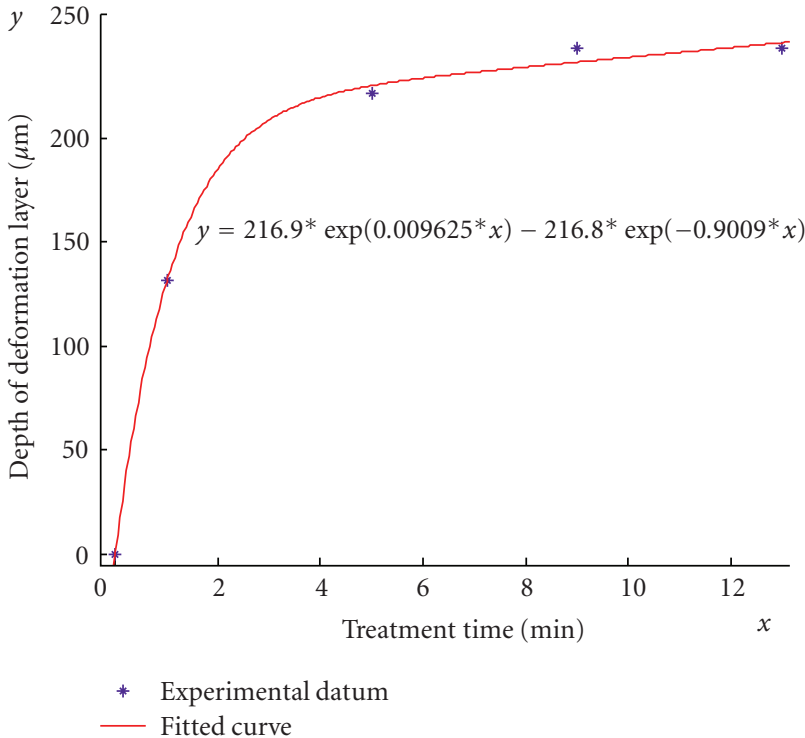

(d)

FIgURE 4: Cross-sectional SEM micrographs close to the SMATed surfaces under different treatment time: (a) 1 min, (b) 5 min, and (c) $13 \mathrm{~min}$. (d) The relation between treatment time and depth of deformed layer.

TABLE 1: Chemical composition of tested materials (wt \%).

\begin{tabular}{lccccccccccccc}
\hline Material & $\mathrm{C}$ & $\mathrm{Si}$ & $\mathrm{Ti}$ & $\mathrm{Ni}$ & $\mathrm{Cr}$ & $\mathrm{S}$ & $\mathrm{Mn}$ & $\mathrm{P}$ & $\mathrm{Fe}$ & $\mathrm{N}$ & $\mathrm{H}$ & $\mathrm{Al}$ & $\mathrm{V}$ \\
\hline 0Cr18Ni9Ti & 0.04 & 0.47 & 0.29 & 8.37 & 17.22 & 0.02 & 1.21 & 0.034 & balance & - & - & - & -
\end{tabular}

size and mean microstrain were calculated from broadening of diffraction peaks, by using formula as follows:

$$
\frac{F W(s) \cdot \cos (\theta)}{\lambda}=\frac{K}{D}+4 \cdot \varepsilon \cdot \frac{\sin \theta}{\lambda},
$$

where $\mathrm{FW}(S)^{D}=\mathrm{FWHM}^{D}-\mathrm{FW}(I)^{D}$ is FWHM of peaks after detracting broadening led by the diffractometer itself; $K$ is a constant, $K=0.89$ here; $\lambda$ is the wave length of the $\mathrm{Cu}$ $K_{\alpha 1}$ irradiation; $\theta$ is Bragg diffraction angle; $D$ is mean grain size; $\mathcal{E}$ is mean lattice strain. By performing a least square fit $(F W(s) \cdot \cos (\theta)) / \lambda$ plotted against $\sin \theta / \lambda$ for all of the measured peaks of a sample, we are able to determine the mean grain size $D$ and the mean lattice strain $\varepsilon$.
The variation of microhardness with depth was measured on longitudinal sections of samples using a MICROHARDNESS TESTER HV-1000 fitted with a diamond indenter. The maximum load for experiment was $0.98 \mathrm{~N}$, and the distance between any two neighboring indentations was $25 \mu \mathrm{m}$. Loading time was $20 \mathrm{~s}$.

\section{Results and Discussion}

3.1. OM and SEM Observations. The cross-sectional microstructures of the SMA treated specimens under different treatment time are shown in Figure 3 and Figure 4, where Figure 3 shows optical micrographs and Figure 4 shows SEM 


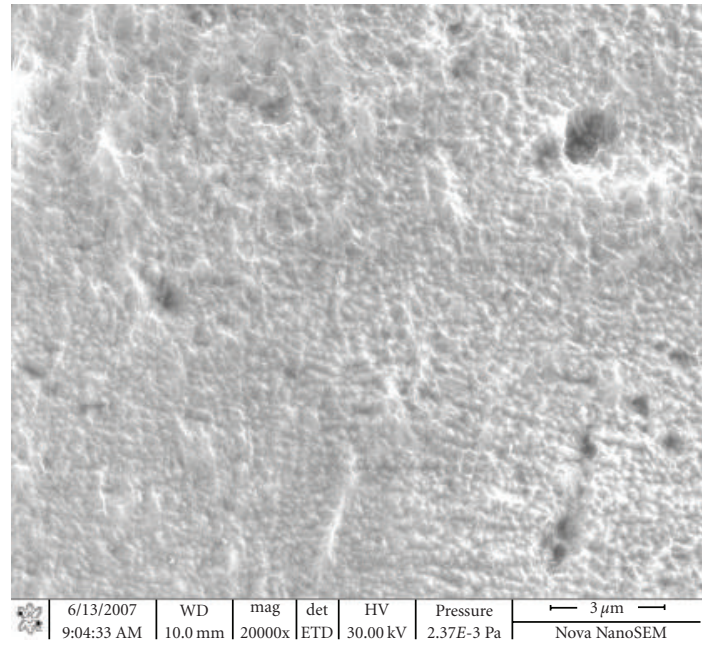

(a)

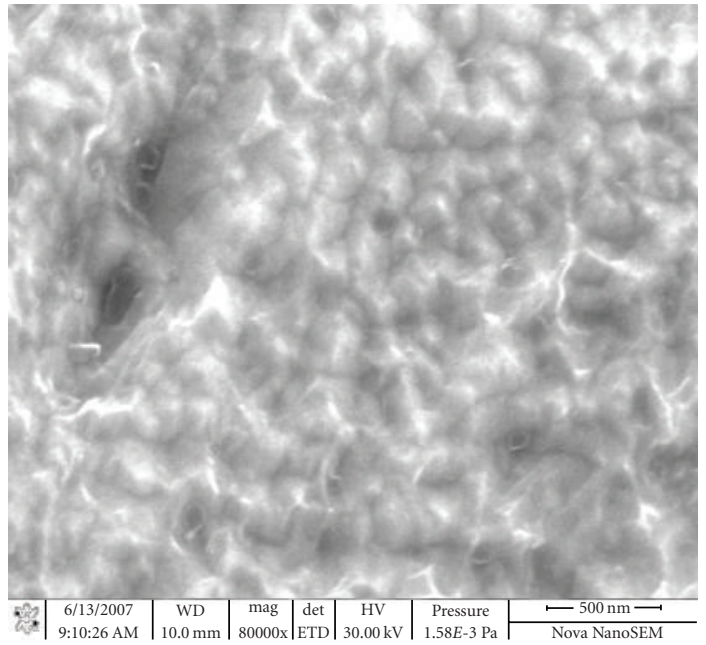

(b)

Figure 5: SEM morphology of the layer $75 \mu \mathrm{m}$ away from the topmost treated surface with magnification of (a) 20000 and (b) 80000.

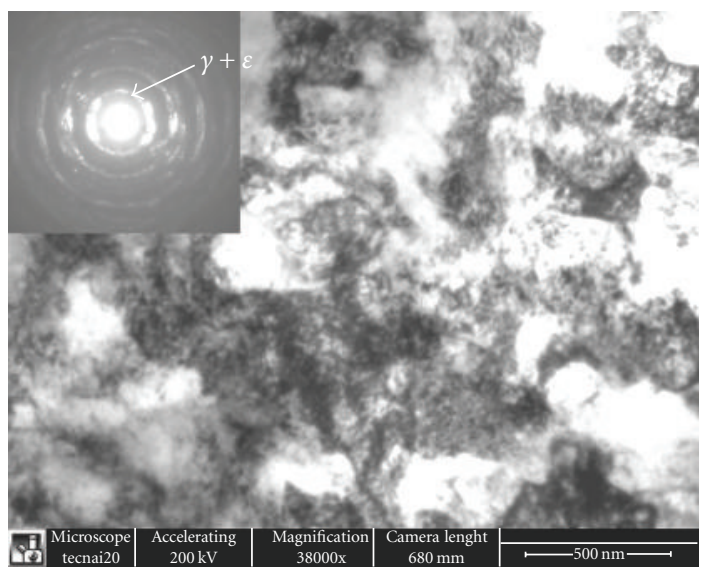

(a)

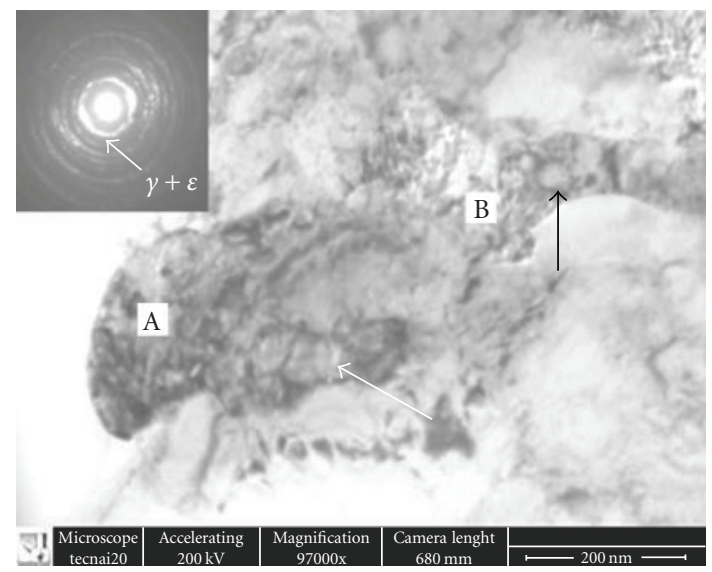

(b)

FIgURE 6: TEM morphology of the layer $75 \mu \mathrm{m}$ away from the topmost treated surface.

micrographs. Due to the limited resolutions, nanograins cannot be directly observed in these graphs. However, these graphs show the depth of the heavy plastic deformation layer. Figure $4(\mathrm{~d})$ is the relation between treatment time and depth of the deformed layer. The depth of heavy plastic deformation layer increases very fast in the initial stage, and it in substance reaches a plateau after treatment of $9 \mathrm{~min}$ or more. The maximum depth of the heavy plastic deformation layer is about $250 \mu \mathrm{m}$. This layer is fiber-like under SEM, and this indicates that the surface layer was severely deformed at high strain rate under the impacting of ball shots with high speed. This is believed to be the premise of grain refinement through SMAT by most researchers.

The rough surface with an arc shape of the samples treated baffles the cross-sectional observation of the topmost treated surface, especially when high resolution microscopes such as SEM and TEM are used for observation. Thus the plane in the surface layer observed by SEM and TEM in this paper was about $75 \mu \mathrm{m}$ away from the topmost treated surface. Figure 5 shows the SEM morphology of the layer about $75 \mu \mathrm{m}$ away from the topmost treated surface with different magnifications. It reveals the presence of subgrains with size of about $100 \sim 200 \mathrm{~nm}$, and few subgrains have sizes within $100 \mathrm{~nm}$. However, these subgrains are supposed to have finer metastructure. This idea is proved to be true by the following TEM observations.

3.2. TEM Observations. Figure 6, taken as well at about $75 \mu \mathrm{m}$ depth from the topmost treated surface, is a typical TEM morphology of this layer. Subgrains with sizes of about 100 200 nm are clearly evident in Figure 6(a), and this is consonant with that observed by SEM. The difference between SEM and TEM observations is that a high density of dislocations can be observed in subgrains and around the boundary of subgrains by TEM. From the corresponding 


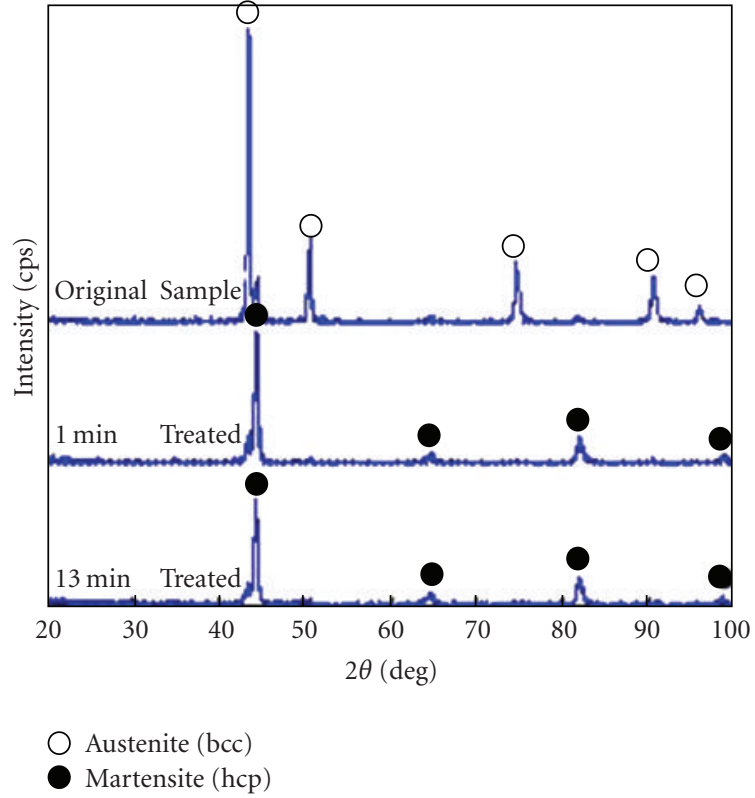

(a)

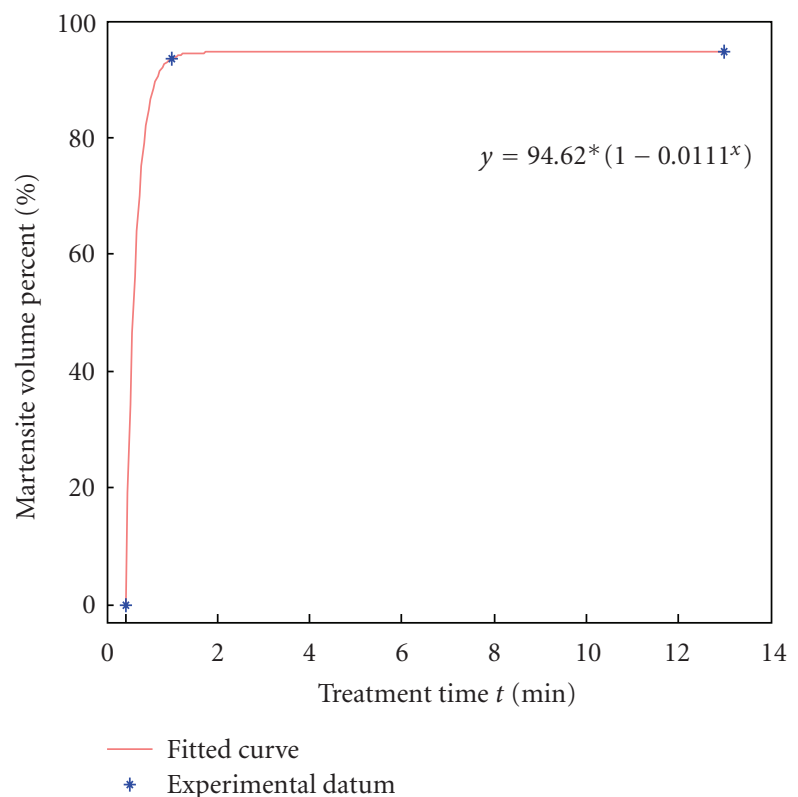

(b)

FIGURE 7: (a) XRD patterns of the surface layer of the SMATed samples treated for different time and (b) variation martensite volume percent with treatment time.

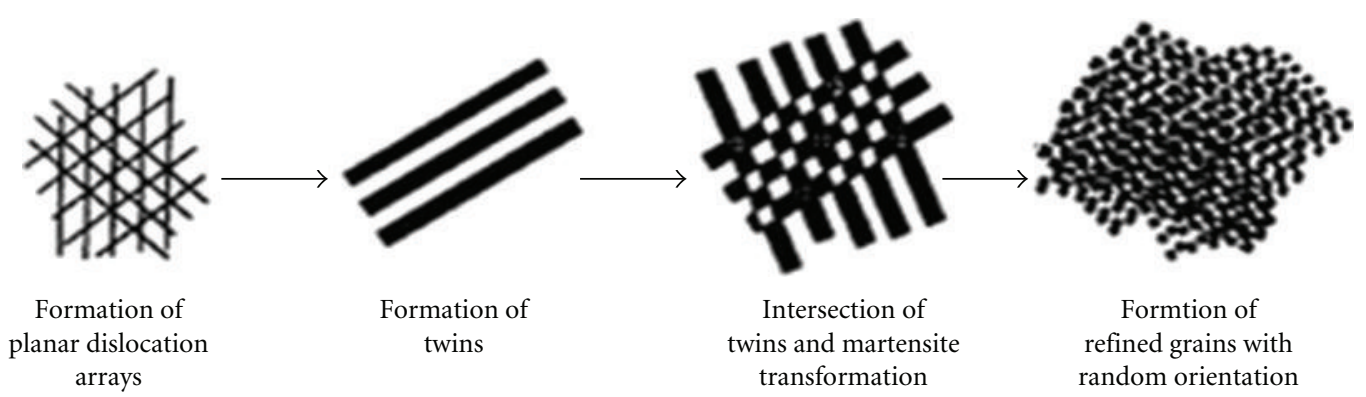

FIGURE 8: Schematic illustration showing the microstructural evolution process of $0 \mathrm{Cr} 18 \mathrm{Ni9Ti}$ surface under surface mechanical attrition treatment [10].

selected area electron diffraction (SAED) pattern, these subgrains have nearly random crystallographic orientation. In addition, one can see that the diffraction rings belong to both $\gamma$ austenite (fcc) and $\varepsilon$ martensite (hcp). Figure 6(b) shows morphology at higher magnification. It reveals the finer metastructure of subgrains. The places marked " $\mathrm{A}$ " and " $\mathrm{B}$ " in the graph represent two subgrains, respectively. One can find that there exist finer particles with sizes under $100 \mathrm{~nm}$ in the region of " $\mathrm{A}$ " and "B". These finer particles are indicated by arrows in Figure 6(b). A high density of dislocations and stacking faults induced by deformation are observed within subgrains as well. From these TEM graphs, one can imagine the process that grains became finer and finer under dislocation activities induced by severely plastic deformation during the surface mechanical attrition treatment. According to the above TEM observations, it is reasonable to deduce that a nanostructured surface layer was developed in the $0 \mathrm{Cr} 18 \mathrm{Ni}$ Ti stainless steel by means of SMAT. This view can be testified by XRD analyses in the following Section 3.3, which gives a semiquantitative value of grain size in the topmost surface layer.

3.3. XRD Results and Corresponding Analyses. In order to quantitatively determine the average grain size of the topmost surface layer after the treatment, XRD analyses were carried out. With consideration of the $\mathrm{Cu} K_{\alpha}$ wavelength and its extinction depth in the stainless steel, XRD patterns reflect the structure information of the surface layer of about $5 \mu \mathrm{m}$ thick. Figure 7 shows the XRD patterns of the original sample, the sample treated $1 \mathrm{~min}$ and $13 \mathrm{~min}$, respectively. For the top surface layer of the sample treated $1 \mathrm{~min}$ and $13 \mathrm{~min}$, evident broadening of Bragg diffraction peaks is seen owing to a grain refinement and an increase in the atomiclevel microstrain. The average grain size was calculated to be about $74.7 \mathrm{~nm}$ and $52.6 \mathrm{~nm}$, for $1 \mathrm{~min}$ and $13 \mathrm{~min}$ specimens respectively. And mean microstrain for $1 \mathrm{~min}$ and $13 \mathrm{~min}$ specimens was $0.15 \%$ and $0.17 \%$, respectively. These results 


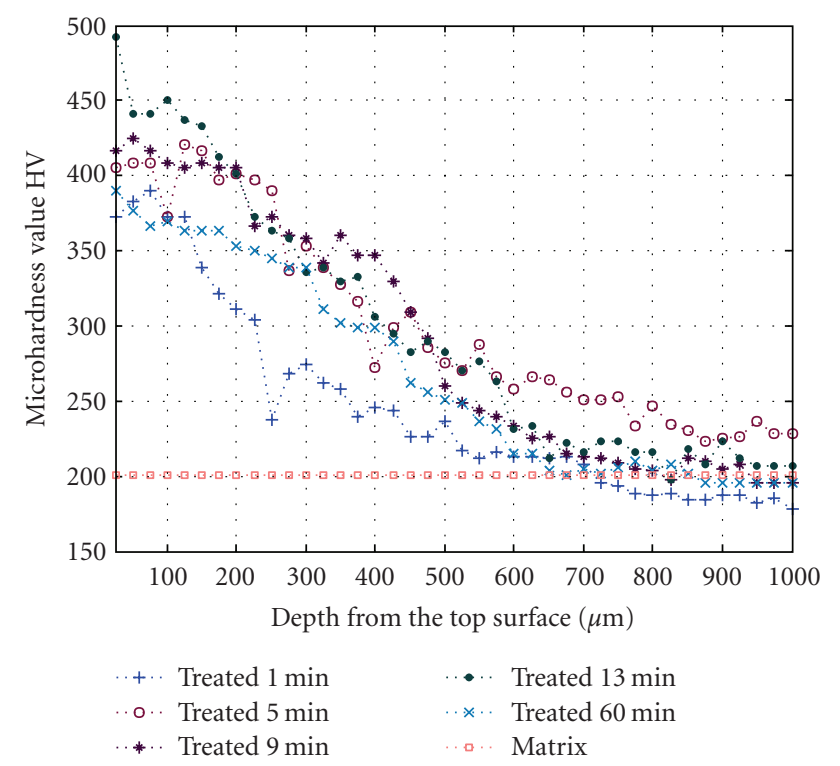

Figure 9: Variation of microhardness along the depth from the treated surface of the SMATed samples under different treatment time.

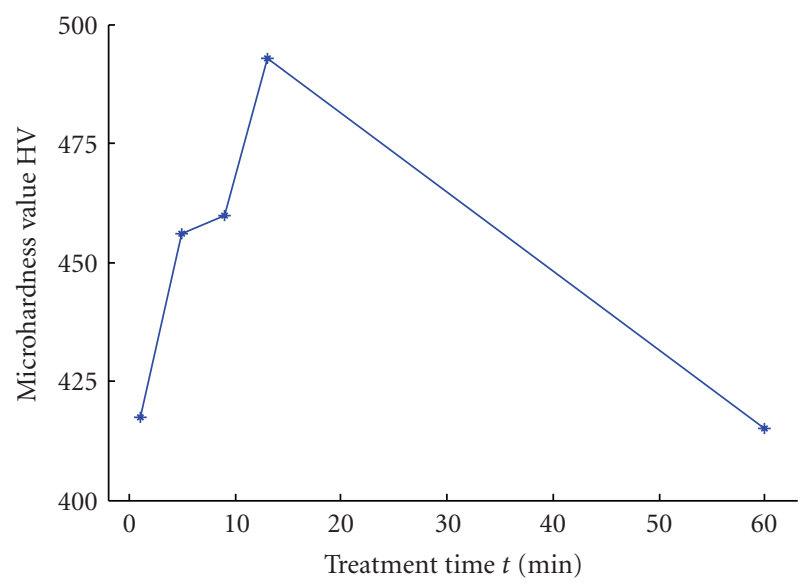

FIGURE 10: Variation of the topmost microhardness with SMAT time.

are basically consonant with the above observations. These results showed that nanograins had formed in the top surface layer and that grain sizes decreased with an increase of treatment time. However, grains cannot be refined infinitely and grain sizes would reach a plateau when dislocation reproduction and dislocation annihilation reached a balance during surface mechanical attrition treatment. Research by $\mathrm{Lu}$ et al. showed that the finest grain size was about $11 \mathrm{~nm}$. Differences between results of Lu and this paper may originate from different SMAT methods, different process parameters, or calculation methods and errors.

Martensite transformation is a prevailing process in the specimens studied here as is indicated in the XRD patterns. XRD patterns shows that martensite is of hcp structure. The volume percent of martensite $\left(V_{M}\right)$ and austenite $\left(V_{A}\right)$ can be determined from the following formula:

$$
V_{A}=\frac{1}{\left(1+I_{\mathrm{M}} / I_{\mathrm{A}} \cdot \frac{K_{\mathrm{A}}}{K_{\mathrm{M}}}\right)}, \quad V_{M}=\left(1-V_{\mathrm{A}}\right) \text {, }
$$

where $I$ is the integrated intensity for (hkl) plane of $A$ or $M$ phase, and $K$ denotes the reflecting capability of $A$ or $M$ phase. The calculation method of $K$ can be obtained from reference [19] listed in the end of this paper. Calculation results are exhibited in Figure 7 (b), which indicated that transformation from austenite to martensite is nearly completed after treatment of $1 \mathrm{~min}$. This also suggests that the surface layer has encountered severely plastic deformation at high strain rate during the SMAT process. It is commonly believed that grain refinement mechanism of $0 \mathrm{Cr} 18 \mathrm{Ni} 9 \mathrm{Ti}$ is as follows [10]: dislocations slip on the (111) plane and arrange themselves in the form of dislocation arrays; formation of single twins and then transition to multitwins under further strain at high strain rate; grain subdivision due to intersection of twins, and formation of martensite at the intersection of twins; further grain refinement to nanoscale by means of incessantly repeating former processes. Finally equiaxed nanograins with random orientation formed under the combination effects of heavy strain at high strain rate and multidirectional loads. Figure 8 gives a schematic illustration of the microstructural evolution process described above. Martensite transformation is believed to be a strain-induced process instead of stress assisted according to the mechanism described above.

3.4. Microhardness Distribution along the Depth of the Deformation Layer. Figure 9 shows the variation of microhardness with distance from the SMATed surface. There is a not so obvious tendency that microhardness increases with the increase of treatment time. These curves can be divided to three parts though they have the same tendency of decreasing on the whole. Taking the sample treated 13 min for example, the thickness of the total deformation layer induced by plastic deformation in $0 \mathrm{Cr} 18 \mathrm{Ni}$ Ti can be identified to be about $700 \mu \mathrm{m}$ from the figure. This depth reflects the thickness that stress field induced by shots'impacting can influence. The decrease of microhardness in the depth from 0 to about $225 \mu \mathrm{m}$ (labeled as Part I) is much slower than that in the interval from about 225 to about $700 \mu \mathrm{m}$ (labeled as Part II), and beneath $700 \mu \mathrm{m}$ is the substrate (labeled as Part III). These results are quite consistent with microstructure observations above. Part I corresponds to the severely deformed fiber-like layer. This layer contains equiaxed nano-grains. According to Hall-Petch formula, grain refinement can result in hardness improvement. It is clear that there is martensite ( $\varepsilon$ phase, hcp) transformation in the surface layer, and martensite is a well-known hard and brittle phase. In addition, work-hardening is an inevitable process when metals are plastically deformed. Just due to these reasons, the microhardness of the top surface is greatly enhanced, about $2 \sim 2.5$ times higher than that of the matrix. Part II can be deemed as a transition layer. 
As there is no martensite transition, hardness increment is mainly resulted from work-hardening, such as movement and multiplication of dislocations, appearance of twins and twin intersections. Correspondingly, the amplitude of microhardness enhancement is lower than that of Part I. This microhardness distribution curve also indicates that the surface of the sample formed a gradient structure under heavy plastic deformation at high strain rate.

It can be noted from Figure 9 that microhardness of the topmost surface varies with SMA treatment time. Figure 10 shows variation of the topmost microhardness with SMA treatment time. According to the above analysis, it is easy to understand why hardness keeps increasing in the former 13 minutes. However, it is interesting to note that the topmost microhardness decreases when treated 60 minutes. The heavy plastic deformation at high strain rate would raise the temperature of the sample, and this phenomenon is very common during the SMA treatment process. Simultaneously, high strain energy is stored in the surface layer due to large strain at high strain rate. Thus, the sample treated 60 min resembles encountering a low temperature annealing process. The surface structure is restored to some extent. So it is reasonable that microhardness would decrease instead when treated for a long time, usually more than 30 minutes.

\section{Summary}

The deformation layer of $0 \mathrm{Cr} 18 \mathrm{Ni}$ Ti induced by surface mechanical attrition just above the substrate can be divided to two parts: the heavily deformed layer and the transition layer. 0Cr18Ni9Ti after surface mechanical attrition has a deformation layer with maximum thickness of about $700 \mu \mathrm{m}$, and thereinto the heavily deformed layer is fiber-like and has a maximum depth of about $250 \mu \mathrm{m}$. The topmost surface is composed of equiaxed nanograins with random orientation, and the finest grain size obtained is about $50 \mathrm{~nm}$. There is martensite transformation in the surface layer of $0 \mathrm{Cr} 18 \mathrm{Ni}$ Ti during the surface mechanical attrition treatment. Martensite is of hcp structure, and it belongs to strain-induced transformation instead of stress assisted. Variation of microhardness along the depth from the top surface indicates the gradient structure of the surface layer. Microhardness of the surface layer is greatly improved after the treatment. Microhardness of the topmost surface can be $2 \sim 2.5$ times higher than that of the matrix when treated for a suitable time.

\section{Acknowledgment}

Financial support from the National Science Foundation of China (no. 50675234) is acknowledged.

\section{References}

[1] R. Birringer, H. Gleiter, H. P. Klein, and P. Marquardt, "Nanocrystalline materials an approach to a novel solid structure with gas-like disorder?" Physics Letters A, vol. 102, no. 8, pp. 365-369, 1984.
[2] K. Lu, J. T. Wang, and W. D. Wei, "A new method for synthesizing nanocrystalline alloys," Journal of Applied Physics, vol. 69, no. 1, Article ID 522, 1991.

[3] U. Erb, A. M. El-Sherik, G. Palumbo, and K. T. Aust, "Synthesis, structure and properties of electroplated nanocrystalline materials," Nanostructured Materials, vol. 2, no. 4, pp. 383390, 1993.

[4] K. Y. Zhu, A. Vassel, F. Brisset, K. Lu, and J. Lu, "Nanostructure formation mechanism of $\alpha$-titanium using SMAT," Acta Materialia, vol. 52, no. 14, pp. 4101-4110, 2004.

[5] K. Lu and J. Lu, "Nanostructured surface layer on metallic materials induced by surface mechanical attrition treatment," Materials Science and Engineering A, vol. 375-377, pp. 38-45, 2004.

[6] G. Liu and L. Zhou, "Surface nanocrystallization technique of engineering metallic materials (Part I)," Journal of Nanoscience \& Nanotechnology, vol. 3, no. 1, pp. 56-60, 2006 (Chinese).

[7] N. R. Tao, Z. B. Wang, W. P. Tong, M. L. Sui, J. Lu, and K. Lu, "An investigation of surface nanocrystallization mechanism in Fe induced by surface mechanical attrition treatment," Acta Materialia, vol. 50, no. 18, pp. 4603-4616, 2002.

[8] X. Wu, Y. Hong, J. Lu, and K. Lu, "Fabrication and nanostructured surface layer of $\mathrm{Al}$ alloy by surface vibrational mechanical attrition," Materials Research Society, vol. 697, pp. 8.14.1-8.14.6, 2002.

[9] H. W. Zhang, Z. K. Hei, G. Liu, J. Lu, and K. Lu, "Formation of nanostructured surface layer on AISI 304 stainless steel by means of surface mechanical attrition treatment," Acta Materialia, vol. 51, no. 7, pp. 1871-1881, 2003.

[10] H. W. Zhang, G. Liu, Z. K. Hei, J. Lu, and K. Lu, "Surface nanocrystallization of AISI 304 stainless steel induced by surface mechanical attrition treatment: I. Structure and property," Acta Materialia Sinica, vol. 39, no. 4, pp. 342-346, 2003 (Chinese).

[11] J. Han, G.-M. Sheng, and G.-X. Hu, "Mechanism of grain refinement for TA17 near $\alpha \mathrm{Ti}$ alloy by high energy shot peening," The Chinese Journal of Nonferrous Metals, vol. 18, no. 5, pp. 799-804, 2008.

[12] X. Wu, N. Tao, Y. Hong, J. Lu, and K. Lu, “ $\gamma \rightarrow \varepsilon$ martensite transformation and twinning deformation in fcc cobalt during surface mechanical attrition treatment," Scripta Materialia, vol. 52, no. 7, pp. 547-551, 2005.

[13] Z. B. Wang, N. R. Tao, S. Li et al., "Effect of surface nanocrystallization on friction and wear properties in low carbon steel," Materials Science and Engineering A, vol. 352, no. 1-2, pp. 144-149, 2003.

[14] W. B. Tong, N. R. Tao, Z. B. Wang, J. Lu, and K. Lu, "Nitriding iron at lower temperatures," Science, vol. 299, no. 5607, pp. 686-688, 2003.

[15] Z. B. Wang, J. Lu, and K. Lu, "Chromizing behaviors of a low carbon steel processed by means of surface mechanical attrition treatment," Acta Materialia, vol. 53, no. 7, pp. 20812089, 2005.

[16] Z. B. Wang, N. R. Tao, W. B. Tong, J. Lu, and K. Lu, "Diffusion of chromium in nanocrystalline iron produced by means of surface mechanical attrition treatment," Acta Materialia, vol. 51, no. 14, pp. 4319-4329, 2003.

[17] X. H. Chen, J. Lu, J. Lu, and K. Lu, "Tensile properties of a nanocrystalline 316L austenitic stainless steel," Scripta Materialia, vol. 52, no. 10, pp. 1039-1044, 2005.

[18] T. Ronald, D. Retraint, K. Lu, and J. Lu, "Fatigue life improvement through surface nanostructuring of stainless steel by means of surface mechanical attrition treatment," Scripta Materialia, vol. 54, no. 11, pp. 1949-1954, 2006. 
[19] A. K. De, D. C. Murdock, M. C. Mataya, J. G. Speer, and D. K. Matlock, "Quantitative measurement of deformation-induced martensite in 304 stainless steel by X-ray diffraction," Scripta Materialia, vol. 50, no. 12, pp. 1445-1449, 2004. 

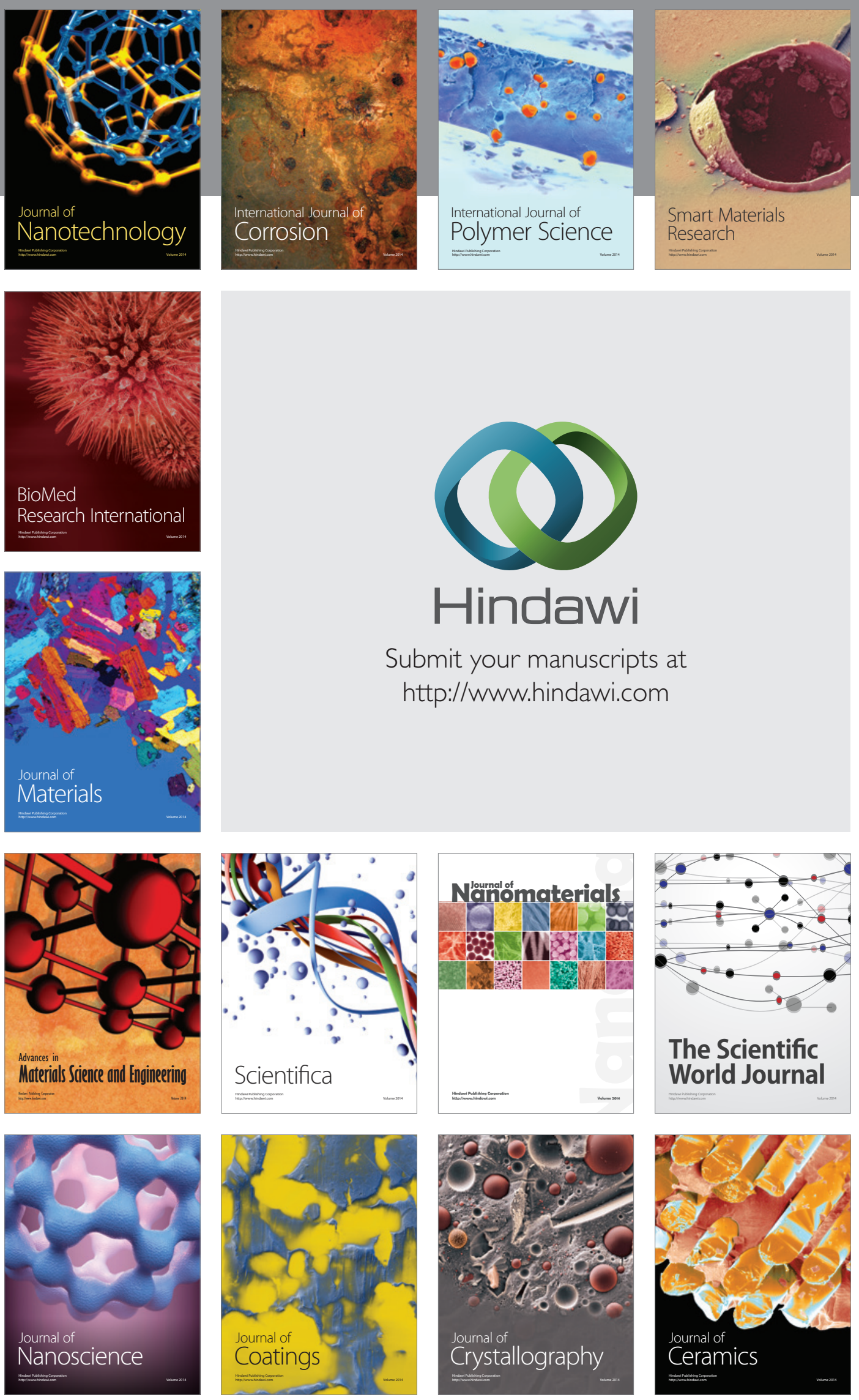

The Scientific World Journal

Submit your manuscripts at

http://www.hindawi.com

\section{World Journal}

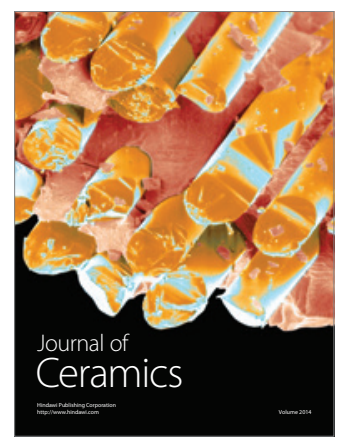

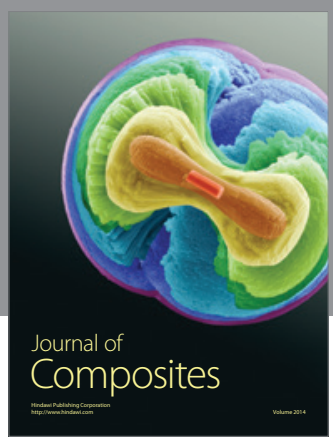
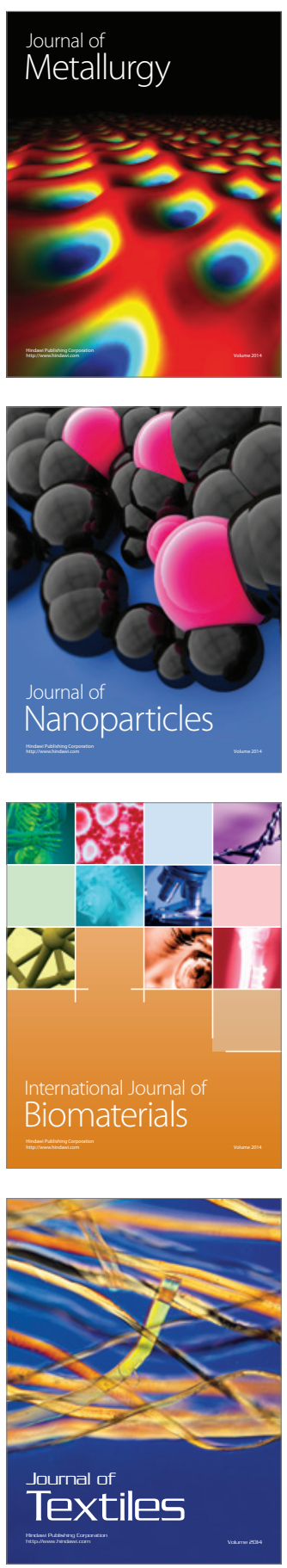